\title{
Incidental diagnosis of torsion of a Krukenberg tumor originating from sigmoid colon cancer
}

\author{
Sang Wook Yi
}

Received: 16 September 2011 /Accepted: 20 October 2011 /Published online: 15 November 2011

(C) Springer-Verlag 2011

Keywords Krukenberg tumor· Torsion · Colon · Ovary

\section{Explanation image}

A Krukenberg tumor refers to gastrointestinal cancer that metastasizes to the ovaries; this tumor was named after Krukenberg, who originally described this pathologic condition of the ovaries in 1896. The prognosis of this tumor is uniformly poor [1]. In the malignant state, the torsion of ovarian tumor is a rare condition because of the adhesions associated with malignant lesions. Two cases of torsion of Krukenberg tumors have been reported so far $[2,3]$.

A 46-year-old woman presented to the emergency department with abdominal pain. Abdominopelvic computed tomography showed a multicystic lesion with a diameter of $6.6 \mathrm{~cm}$ in the right ovary (Fig. 1). Pelviscopy showed a right ovarian mass that had twisted three times in a counterclockwise direction (Fig. 2). Right salpingo-oophorectomy was performed under pelviscopy. Strangely, however, the excised ovarian tissue was friable like caseous necrosis. After the right salpingooophorectomy was completed, the surgical specimen was sent to the department of pathology for obtaining a frozen section. Frozen-section analysis led to the diagnosis of adenocarcinoma; we performed exploratory laparotomy. Moreover, total hysterectomy, bilateral salpingo-oophorectomy, omentectomy, appendectomy,

\section{S. W. Yi $(\bowtie)$}

Department of Obstetrics and Gynecology, Gangneung Asan

Hospital, University of Ulsan College of Medicine,

Gangneung, Gangwon 210-711, South Korea

e-mail: buzzmi@chol.com

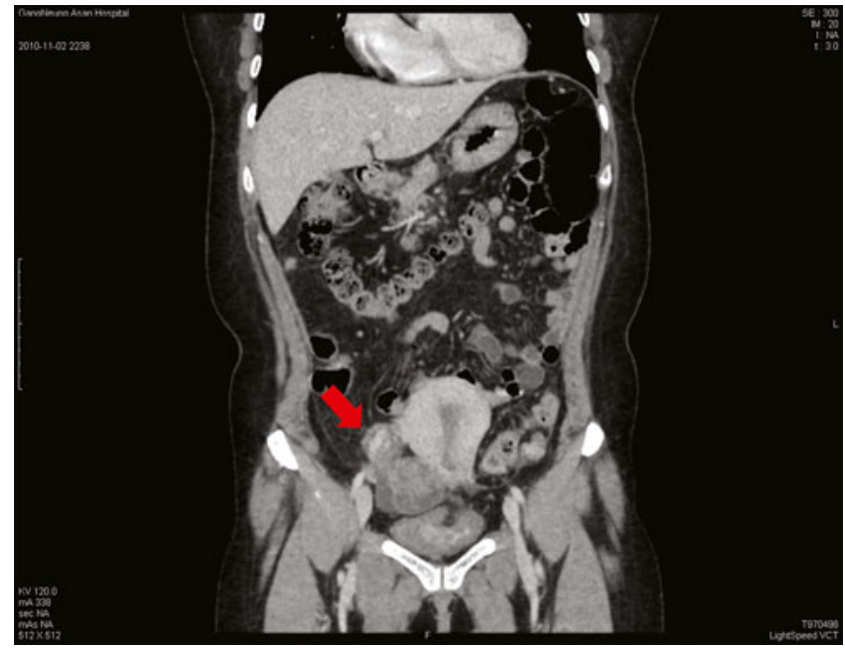

Fig. 1 The coronal section of abdominopelvic computed tomography showed a right adnexal mass with torsion (arrow)

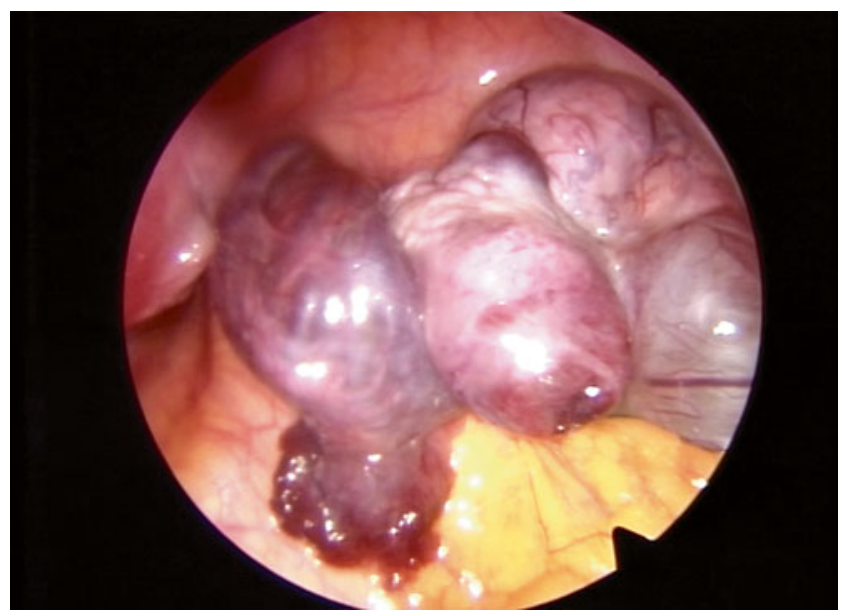

Fig. 2 Laparoscopy of the right ovarian cyst showed that the adnexal pedicle had twisted three times in a counterclockwise direction 
pelvic lymph node dissection, and low anterior resection of the colon were performed. The tumor was pathologically diagnosed as a metastatic adenocarcinoma of the colon. The patient was transferred to the department of oncology, and adjuvant chemotherapy (FOLFIIR\#15) was administered.

Conflicts of interest The authors report no conflicts of interest. The authors alone are responsible for the content and writing of the paper.

\section{References}

1. Krukenberg F (1896) Ueber das fibrosarcoma ovarii mucocellulare (carcinomatoses). Arch Gynakol 50:287

2. Murakami S, Omi M, Yonemori A et al (2011) A case of emergency operation for pedicle torsion of ovarian tumor during bevacizumab therapy. Gan To Kagaku Ryoho 38 (1):139-141

3. Alwyn JE, Zacharin RF (1963) Pregnancy complicated by torsion of a unilateral Krukenberg tumor. Aust N Z J Obstet Gynaecol $41: 125-128$ 